\title{
Desilusión estética: arte $y$ simulacro en Jean Baudrillard
}

\author{
Andrés Ramírez
}

Universidad de Antioquia, Colombia

(c) $\underset{\mathrm{BY}}{(\mathbf{7}}$ 


\title{
Desilusión estética: arte y simulacro en Jean Baudrillard'
}

\begin{abstract}
Resumen: este artículo tiene como propósito abordar la crítica al arte contemporáneo y a la condición humana de la modernidad avanzada que presenta Jean Baudrillard identificando las nociones que permiten comprender la banalización de la imagen y la decadencia de los valores estéticos en el mundo actual. El artículo se despliega en dos momentos; el primero, hace una aproximación al pensamiento estético baudrillardiano y sintetiza los argumentos que soportan sus principales nociones; el segundo momento, profundiza teóricamente la noción de simulacro y establece los factores que inciden en el deterioro de la experiencia estética. Al final de la reflexión se insinúa una conclusión sobre el tema.
\end{abstract}

Palabras clave: arte, simulacro, estética, hiperrealidad, singularidad.

\section{Aesthetic disillusion: art and simulacrum on Jean Baudrillard}

\begin{abstract}
: this article aims to address the criticism of contemporary art and the human condition of advanced modernity presented by Jean Baudrillard identifying the notions that allow us to understand the banalization of the image and the decadence of aesthetic values in today's world. The article has two moments; In the first, an approach is made to Baudrillard's aesthetic thought and the arguments that support his main notions are synthesized; the second moment, theoretically deepens the notion of simulacrum and establishes the factors that affect the deterioration of the aesthetic experience. At the end of the reflection, a conclusion is made on the subject.
\end{abstract}

Keywords: art, simulation, aesthetics, hyperreality, singularity.

Fecha de recepción: 2 de marzo de 2017

Fecha de aceptación: 9 de junio de 2017

Forma de citar (APA): Ramírez Zuluaga, A. (2017). Desilusión estética: arte y simulacro en Jean Baudrillard.

Revista Filosofía UIS, 16(2), doi: http://dx.doi.org/10.18273/revfil.v16n2-2017005

Forma de citar (Harvard): Ramírez Zuluaga, A. (2017). Desilusión estética: arte y simulacro en Jean Baudrillard. Revista Filosofía UIS, 16(2), 111-125.

Andrés Felipe Ramírez Zuluaga: colombiano. Filósofo y docente del Instituto de Filosofía de la Universidad de Antioquia y Seduca. Área de investigación y docencia: filosofía contemporánea y hermenéutica literaria.

Correo electrónico: andresfr-julius@hotmail.com

\footnotetext{
*Artículo de reflexión derivado de investigación.

${ }^{1}$ Este artículo es fruto de la investigación Jean Baudrillard: critica del arte y estética de la vida. Reflexiones acerca del arte y la ilusión, publicado por Publicia (2017).
} 


\section{Desilusión estética: arte y simulacro en Jean Baudrillard}

Es posible afirmar en este instante: no es el arte lo que se ha tornado malo y decadente en sí, sino simplemente que el arte es siempre reflejo de aquello desde donde es creado, no del artista, sino del lugar en el cual la obra ha tenido ocasión. El arte es decadente hoy porque en general la vida humana en todos sus ámbitos ha declinado al más vergonzoso estado en el cual el arte sólo puede expresar su propia ridiculez e impotencia. Se puede decir esto porque un pensador con tinta acida, coraje y lucidez no temió cuestionar las esferas intocables de una sociedad devastada que se regocija cada vez más en sus propios desechos y no puede más que reciclar (re-make) lo que en otro tiempo pudo haber sido glorioso.

Jean Baudrillard elabora su crítica al arte contemporáneo en el marco de su obra El complot del arte. Ilusión y desilusión estéticas (2007). El pensador centra en este caso su estudio en la realidad artística contemporánea y en el contexto visual, publicitario, masivo y de consumo que tanto le influye. A los dos textos que componen el epicentro de la obra: "Ilusión, desilusión estéticas" y "El complot del arte", les sigue una serie de entrevistas al autor que ayudan a comprender y a profundizar sus teorías.

El primer artículo "Ilusión, desilusión estéticas", ha sido seccionado en diversos apartados temáticos de extensión breve, hagamos un rápido recorrido. En el primero de ellos "La ilusión cinematográfica perdida", Baudrillard habla de la evolución tecnológica del séptimo arte y analiza cómo tendiendo hacia la alta definición nos acercamos progresivamente a la "perfección inútil de la imagen" (2007, p. 14). La capacidad de reproducir cada vez con más exactitud la realidad nos priva de ella misma; en lugar de una representación estamos sufriendo el reemplazo de lo real por su reproducción virtual. En "El arte, ilusión exacerbada" el autor dirige su crítica a los simulacros de la pintura-parodia en constante remake, incapaz de proyectar un verdadero valor estético; y así mismo critica las actuales tendencias cinematográficas que sólo buscan colmar la oquedad de las imágenes con exageración y tecnología. 
Los dos siguientes apartados, "La desencarnación de nuestro mundo" e "Imágenes en las que no hay nada que ver", exploran de nuevo la banalidad de las imágenes y el sinsentido de la cotidianidad contemporánea, señalando que el ser humano ha sido arrojado a una obscenidad degradante que testimonia su propio devenir histórico. En "la orgía de las imágenes" el pensador insiste en que la hiperrealidad nos acosa en su virtualización, anulando la realidad a través de formas carentes de profundidad y la estetización de la vida que una publicidad dañina lleva a cabo en un contexto absolutamente mercantilizado. En el segmento "El objeto, amo del juego" el autor afirma que: "Privadas de su secreto y de su ilusión, todas las cosas están condenadas a la existencia, a la apariencia visible; están condenadas a la publicidad, al hacer-creer, al hacer-ver, al hacer-valer. Nuestro mundo moderno es publicidad por esencia" (Baudrillard, 2007, p. 32). En efecto, el exhibicionismo mediático al que asistimos hoy demuestra que el objeto se impone como esencia vital hasta el punto de que incluso el mismo cuerpo es puesto en el juego comercial de publicidad y marketing.

En "Warhol, introducción al fetichismo" el autor se acerca un poco más a la idea de simulacro y de producto visual. Recurriendo a Andy Warhol como paradigma del fetichismo y de la sacralización del signo-mercancía, se expone la gran diferencia que existe entre "la ilusión pura de la técnica" que se conseguía con sus obras y el abuso de "la técnica para producir ilusión" de los vídeo-artístas y creadores de imágenes contemporáneos (Baudrillard, 2007, p. 38). Para concluir el artículo en "Recobrar la ilusión radical", el autor dirige su reflexión hacia la necesidad de nuevos ilusionistas que recuperen el interés por la experiencia mítica de la realidad, abriendo el arte a nuevos horizontes mediante una operación poética, esto es, mediante la ilusión; atribuyéndole un papel relevante en el necesario viraje histórico del ser humano.

El segundo artículo "El complot del arte" retoma muchas de las reflexiones anteriores, pero adentrándose más en el arte. Allí se plantea que la visibilidad se ha vuelto obscena y la ilusión ha desaparecido en el arte que ya sólo aspira a la nulidad, la insignificancia y la banalidad estética. El arte actual se reduce en el patetismo a su evaporación y reciclaje perpetuo, no parece ser un cumplimiento (vollendung) como pensaría Danto (1999). Lejos de eso, este controvertido artículo muestra claramente el posicionamiento de uno de los teóricos más influyentes de los últimos años en la materia, el cual sin duda es contundente e implacable con su crítica; pues presenta el arte como un arrume de escombros más que deja el largo y estrepitoso desastre que es la historia humana. Para Baudrillard, el arte ya no corresponde a una dimensión espiritual ni representa un logro social, sino que plasma una experiencia vital sin intimidad, arrojada a un paroxismo sin precedentes y a una egotista comercialización en donde el sentimiento y el virtuosismo sucumben ante las exigencias del espectáculo y la moda. Lejos de la ensoñación patafísica originaria, el arte se plantea como ironía y desilusión. 
Finalmente, la última parte del libro, las entrevistas, gira en torno a "El complot del arte". En ellas ("A partir de Andy Warhol" — mayo de 1990; "No siento nostalgia de los valores estéticos antiguos"—junio de 1996; "La commedia dell'arte" —septiembre de 1996 y "El arte entre utopía y anticipación" —febrero de 1996) el propio Baudrillard explica su horizonte de reflexión, sus posturas y concreta sus teorías sobre el arte y la sociedad virtual. Analiza ciertos puntos clave de la evolución del arte en la modernidad: el potenciamiento del objeto en Warhol y el giro dramático de los ready-made de Duchamp; a partir de los cuales, la banalidad se volvió estética y la estética se convirtió en banal deteriorando no sólo el mundo del arte sino sobre todo la sensibilidad estética misma del ser humano que cada vez presenta sin vergüenza su mezquindad. Así, el arte es concebido por Baudrillard como parte de lo peor, pues en su simulación banal se despliega como desilusión estética desencantando el mundo y anulando toda posibilidad creativa auténtica y singular.

El artículo de Irina Vaskes "La transestética de Baudrillard: simulacro y arte en la época de simulación total", publicado en el n 38 de Estudios de Filosofía de la Universidad de Antioquia, se dedica a explorar el concepto de simulacro elaborado por el pensador francés a lo largo de su obra. Según afirma Vaskes (2008), Baudrillard define el simulacro como el exterminio de la ilusión, y a la vez como la consolidación de una desilusión total que aniquila la realidad misma y destruye la posibilidad de cualquier representación en la inmediatez de la imagen. Este movimiento devastador, evidentemente, tiene injerencia en el arte y en general en el ámbito de la estética, pues ambos sufren la dislocación de la realidad y la absolutización de la imagen.

El concepto de simulacro no es nuevo, pero no es posible explorar aquí sus diferentes variantes. Esto se debe no sólo a la extensión y complejidad con la que muchos pensadores han tratado dicho asunto, sino al objetivo mismo del presente texto. Baste por el momento decir que aparece a lo largo de la obra de Baudrillard, presente ya en El sistema de los objetos (1968), primer libro del pensador francés, y en El intercambio simbólico y la muerte (1976), tal vez uno de sus libros más reconocidos. En suma, tal como afirma Vaskes (2008), no leer a Baudrillard en clave del principio de simulación sería quizá comprenderlo de una manera inadecuada. En realidad la constelación de conceptos que teje Baudrillard tiene como punto neurálgico la noción de simulacro, tal como se evidencia en Contraseñas (2000), libro donde el autor plantea un útil glosario.

Vaskes (2008) atribuye al carácter no sistemático de la filosofía de Baudrillard la complejidad hermenéutica que se experimenta en su lectura. Lo que podría ser cierto; pero a lo cual habría que añadir, sin duda, que dicha dificultad proviene también del temple anímico de la escritura de este autor. No obstante, esta situación al contrario de obstaculizar los distintos horizontes de reflexión, los abre; en la medida en que el pensamiento de Baudrillard se plantea en un campo de 
juego más allá de la verdad autoritaria y de la lógica tradicional, lo que resulta más adecuado para responder a las exigencias que experimenta el ser humano en la sociedad contemporánea, así mismo lo sostiene el propio pensador francés en su libro El intercambio imposible (1999).

Es necesario indagar entonces por el término de simulacro, para ver qué papel juega éste en la dimensión estética y en particular en el arte desde la perspectiva del pensador francés. Revisar el concepto amorfo de simulacro en el marco de la historia de la filosofía, es una tarea dispendiosa. Se trata, simplemente, de realizar una aproximación al pensamiento de Baudrillard; en cuyo contexto el "simulacro" ha perdido su tradicional relación con la mimesis, pues ya no es una tentativa de representación de algo. Dice Vaskes: "El simulacro de Baudrillard ya no constituye el resultado de la imitación de la realidad, sino lo contrario: su nueva interpretación manifiesta el fin de la imitación y la aniquilación de cualquier referencia" (2008, p. 200).

El sentido del simulacro se revela en un horizonte mucho más complejo, pues ya no es identificable con un proceso de similitud. La comentarista recurre a $\mathrm{El}$ intercambio simbólico y la muerte (1976), libro en el que el autor expone las tres órdenes de simulacros: la falsificación, la producción y la simulación, que corresponden a tres etapas diferentes de la filosofía de la historia allí también planteada. Así, este postulado baudrillariano permite contextualizar históricamente el despliegue del simulacro, hasta su posicionamiento actual, esto es, yendo desde la época de la representación hasta la época de la simulación en el ámbito de la hiperrealidad ${ }^{2}$.

La característica fundamental que destaca en el ámbito de la hiperrealidad, según Baudrillard, es precisamente la disolución de la verdad original, la pérdida de cualquier referente real, y en suma, el hecho de que predomina la reproducción sin fin de modelos superfluos. Dice Baudrillard en La ilusión vital: "Si lo real está desapareciendo, no es debido a su ausencia; es más, hay demasiada realidad. Y es este exceso de realidad lo que pone fin a la realidad" (2002a, p. 57). La proyección virtual, el perfil mediático y la simbiosis pantalla-epidermis impiden cualquier experiencia fenoménica pues el sujeto es reducido a cumplir la función de una terminal receptora y trasmisora de información. La saturación de la realidad conduce a la obnubilación de la percepción y la sensibilidad.

La crisis de la representación es uno de los problemas clave para acercarse a la época contemporánea. Es bien sabida la imposibilidad de sostener clara y distintamente la relación entre el sujeto y el objeto. De hecho, en realidad ambos sucumben; y como afirma Vaskes, ya no se trata del "sujeto garante de la existencia de la realidad, y la razón, creadora de efectos de verdad" (2008, p. 202), sino

${ }^{2}$ Sobre esto ver Baudrillard, 1992 y el artículo citado Vaskes, 2008. 
del camino que ha emprendido el pensamiento y la vida occidental conforme a su declinar. Por eso, comenta críticamente Baudrillard en El crimen perfecto: "la simulación es exactamente esta gigantesca empresa de desilusión - literalmente: de ejecución de la ilusión del mundo a favor de un mundo absolutamente real. Por consiguiente, lo que se opone a la simulación no es lo real..., sino la ilusión" (2000, p. 14).

El simulacro para Baudrillard no es ya la imagen fantasmal que se descubre en el Sofista de Platón en estrecha relación de mutua afirmación con el ćíoos. Tampoco se trata del espacio ficcional en el cual se da el desvanecimiento de la subjetividad y el quehacer literario, tal como pensaron Bataille, Blanchot o Klossowski, a su modo. Para Baudrillard estamos ante algo más aniquilador. El mundo actual se erige como el reino de la tecnología donde la información circula en tiempo real bajo una simulación distorsionada; en la era digital la definición de Baudrillard aparece como el dardo en el blanco. La sofisticación de los medios no ha hecho más que empeorar la crisis representacional que experimenta el ser humano, atrofiando su sistema sensorial y llevando la vida a un punto de superficialidad tal que se volatiza completamente en una obscenidad que expone todo secreto e intimidad, vaciando a su vez, todo deseo y toda potencia.

La oquedad que colma la experiencia del hombre contemporáneo se evidencia en la producción artística de la época. Se puede decir, grosso modo, que al desvanecerse la ilusión (efecto de la realidad) el arte se degenera. Si bien no es justo hacer un juicio generalizado del devenir artístico contemporáneo; al menos es válido mencionar que la implementación de recursos técnicos y digitales, así como de medios masivos de comunicación, ha resultado ser agravante; al menos en lo que respecta al proceso de creación y valoración estética, el arte pasa de la complicidad a la interacción, de la apreciación al life-show. Precisamente, no se debe perder de vista que estos recursos técnicos y digitales, al igual que los medios masivos de comunicación han afectado por igual todas las dimensiones de la vida humana, sobre todo los procesos de participación social, los cuales se generan en una opinión teledirigida y se regulan desde la interacción fingida en un régimen democrático, afirman Baudrillard y varios académicos de diferentes disciplinas como la sociología o la politología.

La desaparición de los acontecimientos que plantea Baudrillard en la simulación, no es por supuesto fácil de asimilar, habría que cotejarla con los postulados de la teoría de la memoria y el testimonio (El arte y la fragilidad de la memoria, 2014), los cuales no han hecho más que politizar y comprometer la experiencia artística con una responsabilidad social. Para Baurdrillard gran parte del mundo del arte contemporáneo responde a una irresponsabilidad generalizada, en ocasiones denigrante. Cruda denuncia que hace que los agudos comentarios del filósofo francés sean considerados por algunos como escandalosos; en efecto, decir que "La guerra del golfo no ha tenido lugar" (1991), o comentar desde la 
perspectiva del intercambio simbólico la caída del World Trade Center (2001), no permite esperar menos. Aun así no se puede olvidar que Baudrillard obviamente no quiere decir que las cosas dejan de suceder, sino que en la experiencia humana la información toma la forma de una estética de lo irretenible y de la desaparición, asimilación y neutralización de lo terrible de una realidad insoportable para el cobarde hombre moderno. En este sentido, dice Vaskes: "Las imágenes y mensajes que "consumimos" son signos tranquilizadores que constituyen nuestra tranquilidad asegurada por la distancia que nos separa del mundo real y, de esta manera, por la exclusión máxima de la realidad" (2008, p. 205).

En efecto, el telón de fondo del pensamiento de Baudrillard es la develación de la miserable condición humana en la época contemporánea y la posibilidad de su transfiguración. Se trata del salto patafísico de la desilusión estética a una ilusión radical, tarea del arte auténtico y singular. Es debido a esto, que el peso en su teoría crítica no recae únicamente en lo devastador que constituye la realidad ni en lo decadente del mundo contemporáneo del arte; sino en el horizonte en el que se cifra la ilusión radical, única estrategia (que en todo caso es fatal) para convertir este mundo en otro siendo el mismo.

Según Baudrillard, de todas formas la mirada es abatida por una pantalla total y en general, es la sensibilidad misma la que se ve completamente atrofiada en un hábitat sin ningún sentido orgánico. De algún modo, en esta contigüidad epidérmica se anula lo humano mismo en una lógica hiperreal. Esta inmediatez de la imagen hace olvidar el carácter paradojal del mundo presentando solo su lado ideal y perfecto; esto es, pretende matizar el hecho de que el dato natural se da entre lo fasto y lo nefasto en una relación sacra.

Se entiende, que Baudrillard está aludiendo de modo crítico al mundo percibido clínicamente, en el cual la profilaxis y la paranoia es equivalente al nihilismo más oscuro, es decir, al odio del hombre por el hombre, como diría Nietzsche (1996). Vaskes lo argumenta de este modo: "se elimina 'lo humano, demasiado humano' en nosotros: nuestros deseos, defectos, locuras, nuestro inconsciente e incluso nuestra sexualidad" (2008, p. 207). La realidad desaparece totalmente homogenizada a los ojos de Baudrillard, pues se ha perpetrado el crimen perfecto al trasladarla mal al espacio de la virtualidad, de la alta definición y de la distorsión mediática; un crimen en el que todo el mundo es cómplice de un complot descarado.

Hay que advertir bien que el simulacro es para Baudrillard una noción filosófica y ontológica, que actualmente aplica para el análisis de los problemas humanos y que se plantea en un horizonte ético y político completamente difuso y perverso. Entiéndase, la vida se desenvuelve ahora en una simulación total que abarca por supuesto todas sus esferas. ¿Pero cómo influye particularmente esta simulación total en el campo estético-artístico? Responder a esta pregunta 
es difícil, y requiere, al menos, mencionar de paso que todo arte en esencia es simulacro, ese es su origen y su fundamento. Pero al decir esto, debe captarse el carácter plurívoco del concepto simulacro, el arte es simulacro precisamente porque tiene el poder de la ilusión y pierde este poder cuando se convierte en expresión simulada.

Pero ya se comprenderá que para el pensador francés no todo arte tiene este poder, en realidad un arte tal se torna cada vez más escaso, en la medida en que parece agotarse en lo que Baudrillard denomina su etapa transestética; lo que "quiere decir que la estética está ya realizada, generalizada y por ello mismo, se resbala a sí misma y pierde su propio fin" (1997, p. 58). Se trata a fin de cuentas de una banalización estética plena que impide cualquier valoración y que el sensato filósofo no se cansó de denunciar y cuestionar.

El arte ya no posee la capacidad de transfigurar la realidad, de metamorfosearla, sino que se ha cosificado y tecnificado. La imagen al dejar de ser figuración o forma simbólica y devenir realidad virtual se presenta en su visibilidad completa, no hay ya intimidad, misterio ni secreto. La imagen es ahora el medio para proyectar sin fin un exhibicionismo, al mismo tiempo vergonzoso y excitante. Una especie de nulidad absoluta posibilita una forma pura e indiferente de la obscenidad humana. El arte hoy en su gran mayoría fabrica imágenes en las que no hay nada que ver, y en las que toda profundidad poética ha desaparecido. Las obras son prótesis estéticas que simplemente saturan el vacío espiritual de la época con la reproducción de un código tautológico, acorde a un sistema completamente decepcionante (como vemos en la obra de Orlan o David Nebreda).

Como resultado acaece una desilusión estética en el mundo, desaparece la crítica de arte y aparece su conceptualización, lo cual no sólo permite la validación arbitraria del mundo del arte que responde a los intereses del mercado, sino que atrofia la interacción perceptual propia de la experiencia estética. Siguiendo a Baudrillard se encuentra que la muerte del arte se remonta al ready-made de Duchamp y que su sepelio aconteció en la Fábrica de Andy Warhol (Factory, New York, 1963-1987). El arte ha sufrido cambios desde 1875 con el descubrimiento del impresionismo y la abstracción, a partir de entonces ha devenido idea, concepto y la ilusión que le servía de fundamento es sustituida por el arbitrio de la voluntad del artista, quien finalmente no es más que una figura comercial que como diría Warhol (1968) aprovecha sus 15 minutos de fama. Lo que pervive hoy no son artistas sino singularidades, son anónimas y rara vez dejan registro en la historia, cosa que realmente poco les importa y los diferencia por completo de los personajes del mundo del arte.

En el momento en el que el arte se convierte en una artimaña conceptual absorbe la posibilidad de la crítica misma; por eso ahora ya se intenta implementar más bien la teoría del arte y no la crítica de arte como antes. La crítica de arte ya 
no tiene cabida porque el sentido de las obras ya no es sensible, ellas han perdido toda significación afectiva. Entendamos:

Cada vez más [...] en cualquier performance, cualquier instalación, cualquier
obra, hay un comentario, hay discurso. Además, se va a buscar a filósofos e
intelectuales para que comenten sobre todo eso [...] Precisamente porque
el arte no cree ya en su propia pulsión estética, [...] y porque ya no está
seguro de su finalidad, necesita asegurarse un lenguaje externo, y para esto
viene a socorrerlo una especie de literatura artística, estética que se produce
incesantemente. Pero esto es un comentario y ya no una verdadera crítica
porque no hay la distancia necesaria para el juicio (Baudrillard 1997, p. 27
citado por Vaskes 2008, p. 215).

Es necesario detener la reflexión un poco en este punto, se debe partir de la evidencia: Duchamp y Warhol convirtieron el objeto banal en obra de arte, Joseph Beuys (1995) por su parte democratizó el arte, ahora todo el mundo es un artista. El arte entra en una repetición cíclica sin precedentes, la consecuencia de ello es el deterioro de la experiencia perceptual sensible y un espectador cada vez más decepcionado y desilusionado. En esta situación es cuando "el artista, inseguro de sí mismo, comienza a buscar desesperadamente incluir al público en la realización de su obra, dejándola abierta para su participación" (Vaskes, 2008, p. 216). Fruto de esta inseguridad aparece todo tipo de instalación o performance. Pero en esta participación no existe la complicidad necesaria para que una forma de la seducción se experimente entre obra y espectador, se trata de una mera simulación, de un consentimiento sinvergüenza e ignorante.

¿Habrá, sin embargo, lugar para recuperar la ilusión, aquella que permite sentir el secreto, la magia de una seducción cada vez más inaccesible? Baudrillard, sensatamente prefiere no precipitarse. Es posible que se pueda recuperar la ilusión, sería milagroso, dado que el diagnóstico no es nada alentador. No obstante, perpetrar el crimen perfecto de exterminar la realidad, esto es, la heterogeneidad que constituye la ilusión de la vida misma es imposible, "es una hipótesis de radiante optimismo" (Baudrillard, 2002b, p. 69).

A la pérdida de la ilusión estética atribuye Verdugo (2010) el carácter apocalíptico del pensamiento baudrillardiano, pues el encuentro entre arte y tecnología ha sido menos benéfico de lo que se esperaba, derivando en la devastadora ironía objetiva. Pero todavía es posible revertir el sentido de la experiencia estética, dice Verdugo: "La ilusión surge pues de las apariencias de la superficie, pero no es esas apariencias precisamente. De hecho, aquí lo real y lo imaginario están en un proceso reversible, de intercambio simbólico" (2010, p. 198) y más adelante agrega: "Este mundo -sin duda mítico- pertenece a una escena primitiva y primigenia de la ilusión y es el contrario de nuestra cultura. Por ello mismo, es nuestro imaginario y nuestra solución extrema" (201). Así el arte configura el canal para transformar la relación perceptual con la realidad, pues "La 
experiencia estética consiste entonces en ingresar en intercambio simbólico con el objeto y el objeto-arte es el que mejor debería permitir ese encuentro" (202).

Con honestidad, se puede decir que es predecible lo insostenible de un sistema perfecto, estable y homogéneo; que en una codificación programática y saturada se desliza hacia una redundancia cíclica, que imposibilita todo devenir. Anota Verdugo: "La ilusión es entonces también el lugar de aparición de lo Otro y el fin de lo Mismo" (2010, p. 202). De ahí pues, la necesidad de que cada ser humano tome una determinación acorde a la crudeza de la situación, propiciando así la transfiguración de la realidad y el viraje hacia otro horizonte epocal. Dice Baudrillard con franqueza a Ruth Scheps en su entrevista El arte entre utopía y anticipación:

No es una cuestión de esperanza; yo no tengo ninguna ilusión, ninguna creencia, pero las formas — se trate de la reversibilidad, de la seducción, de la metamorfosis-, estas formas son indestructibles. Esto no es una vaga creencia: es un acto de fe, sin el cual yo mismo no haría nada (2007, p. 124).

Es posible rastrear los elementos principales del arte contemporáneo según Baudrillard. Se tiene la impresión de que gran "parte del arte actual contribuye al trabajo" (2007, p.11), característica esencial del mundo profano y calculador, fundamentado en el miedo y la inversión económica. El arte, entonces, que se debe al ocio, a la fiesta, a la celebración, a la vida, parece tender a un servilismo sin precedentes. Ya escasea el arte transfigurador, ahora el arte está en función de la disuasión, esto es de la confusión generalizada de los sentidos y del espíritu. También el arte se convierte en una vana forma de llenar el vacío que deja la constatación de que toda representación, es decir, que la imagen y lo imaginario progresivamente se hace inaccesible. Baudrillard llama a esto duelo; pero también llama duelo a la transestética vacua que ha llevado la experiencia corpórea misma al límite. El trabajo del arte disuadir y hacer duelo, enuncia el pensador francés:

trae como consecuencia una melancolía general de la esfera artística, que parece sobrevivirse a sí misma en el reciclado de su historia y de sus vestigios (aunque ni el arte ni la estética son los únicos en verse condenados a este destino melancólico de vivir, no por encima de sus medios, sino más allá de sus propios fines) (2007, p. 11).

Para Baudrillard el mundo entero es presa de una melancolía equivalente al nihilismo más devastador, no se trata de la melancolía romántica, no hay allí nostalgia por la pérdida de la unidad entre hombre y naturaleza, no hay poder creativo, el autor continua así con el análisis nietzscheano. Ocurre más bien algo semejante al sentido originario del término en la teoría hipocrática de los cuatro humores, a saber: Bilis negra del griego $\mu \varepsilon \lambda \alpha \varsigma-\chi 0 \lambda \eta ́$. Vocablo cuya acepción posterior fue la muerte de cualquier tipo de deseo e impulso vital, por lo que derivó en términos clínicos de análisis patológicos como la depresión, trastorno 
que gran número de la población mundial sufre y que sumado al estrés se convierte en nuestro estado de irritabilidad permanente, desilusión vital.

Dice el propio Baudrillard sobre este estado de la sociedad actual: "La melancolía es la cualidad del modo de desaparición del sentido [...] y nosotros todos somos melancólicos" (2005). De esta manera, se comprende porque Baudrillard generaliza la condena de esta melancólica forma de vivir que va más allá de sus propios fines, ya que se basa en la reproducción de un modelo sin ningún fundamento codificado tautológicamente en una programación sistemática que proyecta una falsa esperanza de inmortalidad y confort. En el arte esto se evidencia con el permanente remake de obras clásicas o con los refritos de Hollywood.

Nuestra época de algún modo se sostiene y a veces se reduce a una retrospectiva infinita por medio de la cual avanza, es válido decir pues que nuestra época es hegeliana a costa de sí misma como también apuntaba Derrida (1989, p. 344 ss), esto es, estamos en una época que aun responde a principios dialécticos en donde la determinación binaria de los opuestos instaura una confrontación irreversible que impide la creatividad generada gracias a relaciones heterogéneas. Hace falta reír de esa absolutización de la razón que conlleva a avanzar en el retroceso, y hay que burlar el poder del imperio como dicen Hardt y Negri (2005).

Pero la sociedad actual continúa con el ceño fruncido y lo más terrible se perpetúa en todos los campos -política, historia, moral y también el arte-. En algunas etapas de la historia, la filosofía ha encargado al quehacer artístico una responsabilidad que lo excede, y ciegamente confiado, el ser humano ha creído encontrar allí una esperanza. El arte comprometido y el arte por el arte son una prueba indudable de esto. No obstante, debe quedar claro que el arte no tiene ningún tipo de privilegios, en realidad sufre el mismo declive en el que se sumerge la humanidad entera. El arte no es la esperanza y en todo caso parece no haberla. El arte está tan mal como la historia, ambos intentan redimirse en su detritus y olvidan que sobre ruinas nada se erige y que lo único que queda siempre dicho es el escombro.

Aun así, proponiendo recobrar la ilusión radical, fatal y vital; Baudrillard como filósofo sensato en un mundo completamente devastado por cualquier infinitud de sandeces y atrocidades, abre todavía la posibilidad de una transfiguración del mundo a partir de la ilusión de lo Otro en un giro histórico de la conciencia y la inauguración de otra época. Lo favorable de una operación poética en el mundo y la difusión de una nueva mitología se refleja en la conformación de relaciones vivientes más altas. Por eso es válida la pregunta ¿̇hay todavía una ilusión estética, esto es, una ensoñación que conserve el secreto, la seducción y la magia; una ilusión anestética en la virulencia profusa de la hiperrealidad? Esta ilusión se da en el ensamblaje de un conjunto armónico de partes diferenciadas que componen el todo de una obra, en este sentido afirma el pensador francés que: 


\begin{abstract}
Contra toda la superstición moderna de una «liberación», preciso es decir que no se liberan las formas, que no se liberan las figuras. Por el contrario, se las encadena: la única manera de liberarlas es encadenarlas, es decir, encontrar su encadenamiento, el hilo que las engendra y las enlaza, que las encadena una a otra dulcemente. Por otra parte, ellas mismas se encadenan y se engendran, y todo el arte es entrar en la intimidad de este proceso (2007, p. 42).
\end{abstract}

Es la intimidad que constituye el todo de la obra lo que permite la libertad, esto es, un proceso creativo soberano y armonioso. Este todo íntimo, contratendiente y alternante que está en continuo devenir de acuerdo a una dinámica cósmica, no permite ningún tipo de relación dominante; por el contrario, en tanto singularidad, se trata en cada instante de una heterogeneidad que es lo mismo en tanto que otredad. La objetividad que aparece en este punto es una en la cual los “objetos cuyo secreto no es el de su expresión, el de su forma representativa, sino, por el contrario, el de su condensación y luego su dispersión en el ciclo de las metamorfosis" (Baudrillard, 2007, p. 43).

Entre desgarramiento e indiferencia se debate la experiencia estética contemporánea; no obstante, es en ese espectro de dispersión de las formas en que tiene cabida la ilusión y la puesta en juego de la presencia y del ser. En la ilusión una forma no es superada, y mucho menos sería superada por una idea; en cambio, sí se da una sucesiva mutación de una forma a otra; claramente lo enuncia Baudrillard: "el principio mismo de la ilusión: el de que no hay para la forma más destino que la forma" (2007, p. 44).

El arte es entonces una posibilidad de transfiguración del mundo, mediante la metamorfosis que propicia la ilusión en su juego de simulacros. Una estrategia, que resulta a su modo también fatal. Pero precisamente en esta línea se comprende que el arte es ante todo una reafirmación de la vida; se trata de "recobrar, a través de la ilusión, una forma de seducción fundamental" (Baudrillard, 2007, p. 44). El arte no debe entrar en la disputa por la verdad, ese no es su campo, ya decía un poco antes el pensador francés "todo el arte es primero un trompe-l'oeil, un engaña-ojo, un engaña vida, como toda teoría es un engaña-sentido" (Baudrillard, 2007, p. 44). La fundamentación del arte es mítica, es ese plano en el que el mundo se patentiza como presencia en el instante fulminante de la experiencia.

La nueva mitología es la ilusión más positiva al ser la ilusión vital misma, no es "la ilusión negativa y supersticiosa de otro mundo, sino la ilusión positiva de este mundo de aquí abajo, de la escena operática del mundo, de la operación simbólica del mundo, de la ilusión vital de las apariencias a que alude Nietzsche: la ilusión como escena primitiva, muy anterior, mucho más fundamental que la escena estética" (Baudrillard, 2007, p. 45). El arte fundamentado mitológicamente es soberano y sereno, armoniza las disonancias, reúne a Apolo y a Dionisos como diría Nietzsche, en el espíritu del hombre. 
Si bien es cierto que en general el mundo declina, que es el ocaso ya avisado, ya sabido; es él mismo el único que posibilita una ruptura en la conciencia, cada vez más necesaria. Según parece, se ha de agonizar hasta el milagro de la transfiguración. Por ello es ahora, en este instante, en el que asistimos a un desconsolador silencio en el que se desvanece todo y en el que la devastación deja hecho escombros y ruinas aquello que podría ser bello, preferible y placentero; estamos inmersos en la peor desilusión y urge como nunca la fuerza de una ilusión radical. Es ahora, en este punto crucial la disyuntiva. La situación exige tomar una decisión acorde a la proyección de un nuevo horizonte de pensamiento en consonancia con un sentido destinal preferible.

\section{Conclusión}

En este sentido, progresivamente, el pensamiento de Baudrillard ha ganado reconocimiento en distintos círculos académicos, tanto por la validez como por la contundencia de sus planteamientos, a veces también escandalosos. Se trata de un pensador habitualmente encasillado bajo el rótulo del post-estructuralismo, cuya vigencia, permite templar horizontes de comprensión alternativos para la transformación de la realidad que experimenta el hombre contemporáneo.

En efecto, el arte constituye uno de los blancos centrales de la filosofía crítica de Baudrillard ya que en él se evidencia la degradación a la que ha llegado el ser humano en su devenir histórico. Para el pensador francés vivimos en una sociedad en la que predominan las pantallas y las imágenes banales, vacías y superficiales. Unas imágenes tan reales que han perdido el poder de crear ilusión porque ya no hay cabida en ellas para el secreto o para lo oculto, de tal suerte que el acontecer humano, y con él el arte se sitúa en una hiperrealidad que conduce inevitablemente a lo que Baudrillard llama el culmen de la obscenidad. Definitivamente, en un mundo que se ha vuelto comercial y estético incluso el arte ha perdido su trascendencia, víctima de la extinción generalizada de valores.

Identificar las nociones que permiten comprender la banalización de los valores estéticos en el mundo contemporáneo a partir del pensamiento de Baudrillard, facilita no sólo consolidar una crítica radical al mundo actual y al mundo del arte, sino que en cuanto tal puede perfilarse como una posibilidad de aproximación a la comprensión del devenir artístico contemporáneo y sus múltiples manifestaciones $\varphi$

\section{Referencias}

Baudrillard, J. (1978). Cultura y simulacro. Barcelona: Kairós.

Baudrillard, J. (1991). La guerra del Golfo no ha tenido lugar. Barcelona: Anagrama. 
Baudrillard, J. (1992). El intercambio simbólico y la muerte. Caracas: Monte Ávila Editores.

Baudrillard, J. (1997). Ilusión y desilusión estéticas. Caracas: Monte Ávila Editores.

Baudrillard, J. (2000). El crimen perfecto. Barcelona: Anagrama.

Baudrillard, J. (2002a). La ilusión vital. Buenos Aires: Siglo XXI.

Baudrillard, J. (2002b). Las estrategias fatales. Barcelona: Anagrama.

Baudrillard, J. (2005). Le complot de l'art: illusion et désillusion esthétiques. París: Sens \& Tonka.

Baudrillard, J. (2007). El complot del arte. Ilusión y desilusión estéticas. Buenos Aires: Amorrortu.

Beuys, J. y Bodenmann-ritter, C. (1995). Joseph Beuys: cada hombre, un artista: conversaciones. Documenta (5), 1972.

Danto, A. (1999). Después del fin del arte. Barcelona: Paidós.

Derrida, J. (1989). De la economía restringida a la economía general. Un hegelianismo sin reservas. En La escritura y la diferencia. España: Anthropos.

Domínguez, J. et al. (2014). El arte y la fragilidad de la memoria. Medellín: Sílaba. Hardt, M. y Negri, A. (2005). Imperio. Barcelona: Paidós.

Nietzsche, F. (1996). Humano, demasiado humano. Madrid: Akal.

Vaskes, I. (2008). La transestética de Baudrillard: simulacro y arte en la época de simulación total. Estudios de Filosofía, 38, 197-219.

Verdugo, L. (2010). Jean Baudrillard y la pérdida de ilusión estética. El desarrollo de un pensamiento apocalíptico. Revista Logos, (enero-junio) 17, 189-205.

\section{Cibergrafía}

Baudrillard, J. (2005) Simulacra and simulation. Recuperado de http://www.egs.edu/ faculty/jean-baudrillard/articles/simulacra-and-simulations-xviii-on-nihilism/ 